\title{
Imputabilidad de las personas jurídicas en el Derecho Administrativo Sancionador
}

\author{
Ronald A. Euseda Aguilar' \\ Docente Utec \\ eusedalaw@gmail.com \\ Recibido: 22/11/2016 - Aceptado: 24/01/2017
}

\section{Resumen}

Desde el punto de vista punitivo del principio de culpabilidad, ha sido difícil crear una dogmática que especifique la forma de imputar delitos o infracciones a personas jurídicas.

Es así que en una época el Derecho penal prohibió la responsabilidad penal de personas jurídicas, paradigma que cada vez está cambiando en las legislaciones comparadas. En cambio, el Derecho Administrativo Sancionador siempre ha contemplado las sanciones a personas jurídicas; $y$, a pesar de tener en tiempo ventaja sobre ello, en la actualidad no se ha creado una teoría que logre culminar dicha tarea.

\section{Palabras clave}

Derecho administrativo, actos administrativos, funcionarios públicos, sanciones administrativas, acción penal, culpa jurídica-El Salvador

\section{Abstract}

From the punitive point of view of the principle of guilt, it has not been easy to create a dogma which specifies the manner in which crimes or offences can be attributed to legal persons.

Some time ago, Criminal Law prohibited the criminal accountability of legal persons, a paradigm which continually evolves in comparative legislation. In contrast, the Sanctioning Administrative Law has always taken into account sanctions to legal persons, and even though it has been doing so for a long time, no theory has yet been created to achieve this task in Criminal Law.

\section{Keywords}

Administrative law, Administrative acts, public officials, Administrative sanctions, penal action, legal fault-El Salvador.

\footnotetext{
Docente de Derecho Administrativo y Mercantil de la Universidad Tecnológica de El Salvador (Utec). Abogado, notario y árbitro. Licenciado en Ciencias Jurídicas por la Universidad de El Salvador, máster en Estudios Judiciales impartida en conjunto con la Universidad Católica de El Salvador, la Universidad Doctor José Matías Delgado y la Escuela Superior de Economía y Negocios, con diplomaturas en Derecho Procesal Civil y Mercantil, Derecho Aduanero, Criminalística y Medicina Legal, Investigación Jurídica y Métodos de Resolución Alterna de Conflictos. .
} 


\section{Introducción}

En nuestro sistema jurídico las personas jurídicas no constituyen centros de imputación penal. ${ }^{2}$ El principio societas delinquere non potest ${ }^{3}$ se reúsa determinantemente a reconocer la capacidad de acción de las personas jurídicas, por lo que mantiene un régimen de impunidad vigente en materia societaria. Dicho principio, inquebrantable dentro de nuestro sistema penal, es totalmente desvanecido en el Derecho Administrativo Sancionador. Los falaces motivos que todavía fundamentan la vigencia de la incapacidad de culpabilidad no tienen aplicación en elámbito administrativo. ${ }^{4}$ Decimos "aún" dado que existe todo un progreso teórico que ampara la capacidad de la culpabilidad de las personas jurídicas, así como la aceptación de la responsabilidad penal de las personas jurídicas en España ${ }^{5}$ y otros países de la región latinoamericana. ${ }^{6}$
Y es que, resulta lógico que, desde el momento que el Derecho Administrativo Sancionador puede imponer sanciones de multa a los entes jurídicos, también pueda hacerlo el Derecho penal mediante las penas de multa. ${ }^{7}$ Lo que en definitiva significa que la inimputabilidad de las personas morales es una mera decisión de política legislativa. Finalmente, la posibilidad de sancionador a las personas jurídicas en el área administrativa ha constituido una de las principales diferencias entre los dos grandes sistemas punitivos, al menos en el Derecho Continental. ${ }^{8} \mathrm{Tal}$ diferencia constituye, para algún sector de la doctrina, una contradicción con el principio de culpabilidad, ${ }^{10}$ en tanto se impone sanciones a una ficción, es decir, un ente ficticio carente de cuerpo y, por ende, incapaz de manifestarse por medio de acciones, igualmente carente de voluntad, por ello, de intención o capacidad de diligencia, resultando imposible exigir la comprensión de su antijuricidad.

2 Nuestro sistema jurídico pertenece al llamado Derecho Continental, del cual hemos sido influenciado. Es por ello que implicamos la imposibilidad de sancionar penalmente a las personas jurídicas. Tal como establece Palma Del Teso, en la actualidad conviven en el ámbito penal dos sistemas. En el sistema jurídico del Common Law se admite la responsabilidad penal directa de las personas jurídicas. En Inglaterra, la persona jurídica puede ser responsable de todos los delitos, con excepción obviamente de aquellos que un ente de esta naturaleza no puede cometer. Lo mismo sucede en Canadá, Estados Unidos y Australia. Por el contrario, en el sistema de Derecho Continental tradicionalmente se ha defendido la aplicación del principio societas delinquere non potest. (Teso, p. 191).

3 Comenta Beotas López: "El axioma societas delinquere non potest es la frase que se resume y sintetiza la imposibilidad de hacer responsable penal a las personas jurídicas. Su base se ha encontrado bien en la incapacidad de sufrir penas privativas de libertad, bien en su incapacidad de realizar acciones en sentido jurídico penal, pues falta la voluntad en términos psicológicos naturales, todo lo cual al ser extrapolado al ámbito administrativo sancionador, como indica Alejandro Nieto, somete a una dura prueba el dogma actual de la exigencia de culpabilidad" (López, Madrid. , p. 145).

4 Bonilla Sánchez realiza un resumen de la posición en general que contradice la capacidad de culpabilidad de las personas jurídicas. La tradición jurídica ha consolidado la idea de que la pena solamente puede ser la respuesta del ordenamiento al comportamiento de un individuo, pues únicamente el hombre es capaz de dolo o culpa. Estos negadores de la punibilidad de las personas jurídicas, que son mayoría en la doctrina, afirman que solo el hombre es competente para tener derechos y deberes; él exclusivamente tiene conocimiento, voluntad y capacidad subjetiva de querer y emplear el dolo. Se asientan en la vertiente psicológica o intencional de la culpabilidad, de la que carecen las colectividades, en la cual la pena es un reproche ético-social imposible de dirigir a la empresa; en que esta carece de voluntad propia distinta de la de sus órganos de administración y dirección; en que no puede ser considerada persona en Derecho penal porque está falta de autoconciencia, de capacidad para comprender el significado de la norma y hacerla suya o rechazarla; y en que tampoco puede ser destinataria de la norma penal porque no posee libertad de acción (Sánchez, 2010, pp. 276-277).

5 Ese cambio hacia la previsión sistemática de consecuencias jurídicas aplicables a las personas jurídicas, en razón de hechos delictivos, se transformó sustancialmente al reconocerse de forma expresa la responsabilidad penal de las personas jurídicas mediante la Ley Orgánica 5/2010, de 22 de junio, de reforma del Código Penal. En su virtud, se instituyó y reglamentó por primera vez en nuestra legislación penal la responsabilidad penal de las personas jurídicas (Art. 31 bis), con un catálogo de penas aplicables directamente a aquellas (Art. 33.7) y un sistema de aplicación de estas penas igualmente singular (Art. 67 bis). (Pasamar, Estudios Penales y Criminológicos, p. 222).

6 Véase los casos de Chile en la Ley n. 20.39 y en la Ley Sobre la Responsabilidad Penal de las Personas Jurídicas; en Colombia, la Ley 1474 de 2011.

7 Tal como ha expuesto Gómez Tomillo, haciendo una crítica en términos similares: "Semejante punto de vista acaba encerrando un auténtico fraude de etiquetas porque bastaría con cambiar la calificación de la medida punitiva contra las personas jurídicas para que resultase aceptable. Téngase en cuenta que frente a las personas jurídicas la Administración puede imponer prácticamente cualquier medida sancionatoria, en iguales términos que el Derecho penal, toda vez que única sanción que tiene vedada, la pena de prisión, carece de toda lógica frente a entes colectivos" (Tomillo, 2010, p. 30). Recuérdese también que, conforme al concepto de sanción administrativa que la Sala de lo Constitucional ha adoptado, resulta que la diferencia entre multa administrativa y multa penal es solo formal, en cuanto a la autoridad que la impone, dado que resultan ontológicamente iguales.

8 Debe mencionarse que dicha diferencia no es sustancial, y solo ha sido coyuntural. Véase el ejemplo de España, que actualmente ha admitido la capacidad penal de las personas jurídicas, por lo que, no puede decirse que siga siendo una verdadera diferencia entre ambos ámbitos.

9 La doctrina ha encontrado una nueva contradicción con el principio de culpabilidad en el caso de que la imposición de la sanción se haga recaer sobre la persona jurídica y no sobre las personas físicas, que realmente son los artífices de la infracción. El razonamiento no reviste ninguna especial complejidad dogmática que dificulte su comprensión: las conductas requieren un contenido volitivo, y este, por naturaleza y definición, es exclusivamente individual y, por tanto, impropio de las personas jurídicas. Estas vienen a ser personas inanimadas, que adquieren el ritmo que le impelen los portadores que las ocupan y que, conforme el principio de culpabilidad analizado, debieran ser las que respondan de las consecuencias jurídicas de sus conductas (M.J., 2008, p. 206).

10 Resulta curioso, por un lado, que parte de la doctrina considere conculcado el principio de culpabilidad, con la admisión de la responsabilidad de las personas jurídicas. Sin embargo, la práctica ha demostrado que es sostenible de la imputación a entes societarios. De manera que esta 
Sin embargo, desde un punto de vista realista, es imposible negar la capacidad de cometer infracciones a las sociedades. ${ }^{11}$ Por lo que, el Derecho no puede dejar en impunidad tales actos. Por principio de culpabilidad es imposible fundamentar una sanción solo por el reconocimiento de la potestad de infringir de las sociedades. Hace falta, para ello, fundamentar la comisión bajo el prisma de la culpabilidad. Sin embargo, la dificultad de encajar el concepto de imputabilidad —creado dentro de la teoría del delito para personas naturales y trasladado al Derecho Administrativo Sancionador - ha llevado a que no exista consenso dentro de la doctrina administrativista, en cuanto al elemento culpable, para las personas jurídicas. La doctrina se limita a suprimir el elemento subjetivo de la infracción, proponiendo una responsabilidad objetiva para las personas jurídicas. ${ }^{12}$ Otro sector de la doctrina se ha mantenido al margen, sosteniendo la exigencia de la culpabilidad para las personas jurídicas. En ese mismo sentido, la jurisprudencia española se ha pronunciado mediante la Sentencia del Tribunal Superior de Justicia de Andalucía del 11 de enero de 2001, en la que se reconoce la culpabilidad de las personas jurídicas de un modo distinto.

- $\quad$ No significa que, para el caso de las infracciones administrativas perpetradas por personas jurídicas, se haya suprimido el elemento subjetivo de la culpa, sino que ha de aplicar necesariamente de forma distinta; lo cual, no comporta preterición del principio de culpabilidad, ni del de personalidad de la sanción, sino acomodación de estos principios a la responsabilidad de las personas jurídicas, en las que falta el elemento volitivo en sentido estricto, pero no la capacidad de infringir las normas a las que están sometidas (M. Rebollo Puig; M. Izquierdo Carrasco; L.A. Alarcón Sotomayor; A.M. Bueno Armijo, 2010, pág. 265). ${ }^{13}$

- $\quad$ Dicho entendimiento, distinto de la imputabilidad de la autoría en la infracción perpetrada por personas no jurídicas, nace de la misma naturaleza de ficción jurídica a la que responden estos sujetos: falta en ellos el elemento volitivo en estricto sentido, pero no la capacidad de infracción de la normativa a la que deben someterse, sin ser ajenos por ello a la reprochabilidad que se genera al conculcar el bien jurídico cuya protección se intenta con la norma transgredida por aquellos (Santos, 2001, pág. 82).

De esta manera se comienza a crear una teoría de la infracción administrativa de la persona jurídica. El primer elemento es la aceptación de su existencia como una ficción, que en definitiva significa que se le ha reconocido su potest delinquere, y que debe amalgamarse con un criterio de imputabilidad, o si se prefiere, de culpabilidad. Para ser más precisos, emplear un criterio acorde, de reproche, para la persona jurídica. ${ }^{14}$

\section{Criterios de imputación}

En el Derecho Penal se entiende la imputación como atribución de un delito. Así, para Kuri, "el término 'atribución' debe entenderse como la relación por la cual la conducta humana y su resultado se subsumen en un tipo penal, y como consecuencia del tal subsunción se decide

teoría resulta pionera y propia del Derecho Administrativo Sancionador, es decir, contrario a lo que suele pasar, no existe préstamo del Derecho penal. Por lo que, si se quiere ser congruente, habría que pensarse cuál es la verdadera contradicción. Ya que, desde la aceptación de la teoría de ius puniendi único por medio de la sentencia de inconstitucionalidad de ref. 3-92 (Ac) 6-92 del 17-12-1992, es posible aceptar en consecuencia la responsabilidad penal de las personas jurídicas, por lo que, a mi parecer, la verdadera contradicción consiste en otorgar igualdad en dos fenómenos sancionadores, para después desconocerlos por medio de la legislación. ¿Cómo es posible mantener la responsabilidad de las personas jurídicas en el Derecho Administrativo Sancionador y después negarla en el Derecho penal, si ambos fenómenos son ontológicamente iguales?

11 A este punto se refiere NIETO explicando que el tema puede abordarse desde dos puntos de vistas, el dogmático y el realista. Por el primero el punto de vista tradicional donde no puede exigírsele responsabilidad a una persona jurídica, cuestión que se traspola al Derecho Administrativo Sancionador. El segundo punto de vista se apoya sobre fenómenos observables, principalmente la legislación que acepta la posibilidad de la comisión de infracciones por parte de las sociedades, así como su efectiva realización por lo que no puede ignorase tales resultados (Nieto, 2012, págs. 392-393).

12 Lo que en definitiva sería inadmisible en nuestro sistema jurídico, por ser contrario al principio de culpabilidad, ya que, como se ha mantenido en este trabajo, la culpabilidad prohíbe toda imputación por la mera causación de un resultado, ello incluye a las personas jurídicas.

13 En el mismo sentido, Torrado establece: "No queda más que decir, en un sentido estricto y literal, que las personas jurídicas no pueden ser culpables, ni tampoco inocentes. No nacen ni mueren, ni compran ni venden, pero el derecho finge todo ello. Puesto que de esta ficción jurídica se trata, la responsabilidad con culpa de estas personas jurídicas tiene que explicarse de una manera distinta a la culpa y la inocencia de una persona física" (Torrado, 2008, p. 172).

14 Al respecto, Choclán Montalvo opina: "Si la culpabilidad jurídico-penal se fundamenta en el libre albedrío, y, por tanto, en la capacidad de reproche por no haberse comportado el sujeto conforme a la norma, podremos concluir que la atribución de culpabilidad a la persona jurídica constituye también una ficción: la ley considera a la persona jurídica como un sujeto con voluntad, aunque no la tenga realmente; y es la ley la que le reconoce capacidad jurídica y de obrar, aunque realmente no actúe" (Montalvo, 2009, p. 292). 
la exigencia de responsabilidades penales" (Kuri, 2013, p. 1). De esta manera, análogamente podemos entender que imputación o atribución de una infracción administrativa a una persona jurídica como la relación por la cual la conducta de la persona jurídica y su resultado se subsumen en un tipo infraccionario, y, como consecuencia de ello, se decide la exigencia de responsabilidades administrativas.

De esta manera se plantea el primer cuestionamiento del tema. Si la persona jurídica es una ficción, un ente inanimado carente de cuerpo, ¿cómo realiza acciones u omisiones que infrinjan la ley? ¿Cómo atribuir o cómo reprochar a la persona jurídica dicha infracción? A estas preguntas la doctrina ha dado respuestas mediante la mutación del entendimiento de la acción de la persona individual. Entendiendo que el cuerpo de las personas jurídicas lo constituyen todos quienes la conforman. Es decir, que el ente ficticio se auxilia de sus componentes individuales para llevar a cabo sus propios fines. De esta manera, la doctrina ha sido muy ingeniosa; y al menos pueden encontrarse dos posturas para atribuir la responsabilidad a una persona jurídica. Podemos mencionar la teoría del órgano y la teoría por defecto de organización.

\section{Responsabilidad por atribución del hecho de otro}

Dicha teoría ha sido denunciada por transferir responsabilidad de un sujeto a otro, es decir, de la persona natural a la persona jurídica (Sánchez J.S., 2009, p. 30). En la teoría del órgano, se entiende que tanto directivos, administradores o gestores, incluso empleados, son partes de la persona jurídica, es decir, órganos de esta. Por ello, cuando un órgano actúa, es un acto de la persona jurídica misma. Giannini realiza unas cuantas acotaciones que pueden predicarse de manera sumaria de dicha teoría: “En la relación orgánica, el titular del órgano imputa todos los aspectos de los actos realizados a la persona jurídica a la que pertenece el órgano... el acto materialmente adoptado por el titular del órgano es de la persona jurídica y al titular del órgano no se le imputa nada en absoluto" (Giannini, 1991, p. 161).

- Para Silva Sánchez, el modelo de responsabilidad por atribución a la persona jurídica presupone la comisión de un hecho delictivo completo por una de las personas físicas integradas en su seno, normalmente por alguna de las que integran sus órganos o la representan. Según tal modelo, la responsabilidad por ese hecho delictivo se transfiere a la persona jurídica, en la medida en que se considera que los actos de dichos órganos, en virtud de la relación funcional existente entre estos y aquella, son, también, de esta última. Tales hechos, por lo demás, pueden ser de comisión activa o, también, de comisión por omisión, en la medida en que los órganos omitan deberes de vigilancia, de coordinación o de selección, que den lugar a la conducta delictiva activa de un integrante de la empresa situado en sus niveles inferiores. Lo que queda abierto en todo caso, para este modelo, es la cuestión del título en cuya virtud la responsabilidad por ese hecho puede ser transferida a la persona jurídica (Sánchez J.S., 2009, p. 30).

Como puede observarse, esta teoría facilita la conexión del elemento culpable de la persona jurídica, por acciones de sus órganos. Sin embargo, entendida la culpabilidad como reproche, no se logra entender el titulo o reproche hecho a la persona jurídica. Cuando se habla de la culpabilidad, para las personas naturales, el reproche consiste en la denuncia de no haber actuado de una forma distinta cuando podía hacerlo, pero en el caso de las personas jurídicas no es fácil distinguir dicho título.

\section{Responsabilidad por hecho propio}

La segunda teoría que la doctrina ha creado, respecto de la culpabilidad de las personas jurídicas, es la de por defecto de organización. Las normas punitivas entendidas como normas valorativas, es decir, que pretenden motivar la conducta de las personas, para que estas determinen su conducta conforme al Derecho. Entendido esto así, en el caso de las personas naturales, se motiva en el sentido de que no infrinjan las normas cometiendo las infracciones tazadas en la ley, mediante el debido deber de cuidado $3 / 4$ culpa o negligencia $3 / 4$, o la abstención de que querer cometer el ilícito $3 / 4 \mathrm{dolo} 3 / 4$; de lo contrario, se le reprocha el no haber actuado de otra forma. Cuando se trata de personas jurídicas, tal motivación no radica específicamente en el dolo o la culpa de manera directa, sino que se busca que la persona jurídica, entendida como un ente organizado o corporativo, adopte la organización específica con la que se evite cometer infracciones administrativas, en nuestro caso. De esta manera se imputa a la persona jurídica de manera directa, no se transfiere ninguna responsabilidad de sus órganos. Esto debe entenderse como el reproche de no 
haber adoptado una organización que posibilite que órganos cumplan con todas sus obligaciones en forma debida. Para ser más preciso, podría resumirse el reproche de las personas jurídicas en la hipótesis de "poder organizarse de otro modo" (Sánchez J.S., 2009, p. 30). Este deber de organización comprende no solo mera ejecución de un plan, sino también establecer los mecanismos de vigilancia que posibiliten el efectivo cumplimiento de dicho plan.

Para Silva Sánchez "resulta más que dudoso si la culpabilidad por defecto de organización es expresión de una culpabilidad en sentido estricto de la persona jurídica o, por el contrario, una regla de transferencia de responsabilidad a la persona jurídica por el hecho culpable de las personas físicas que, en el seno de la misma, infringen los deberes de organización y vigilancia que recaen sobre ellos" (Sánchez, J.S., 2009, p. 30). Al respecto, Gómez Tomillo y Sanz Rubiales opinan que tal "culpabilidad es particularmente patente en las hipótesis en las que el hecho protagonizado por la persona jurídica no se debe a la actuación particular de un sujeto enmarcado en aquella, sino al cúmulo de operaciones individuales de personas físicas insertas en la estructura propia del ente colectivo de que se trate" (Tomillo, 2010, p. 524). Si bien esta teoría trata de imputar una infracción de manera directa a la persona jurídica, siempre es necesario un hecho de conexión con la acción de personas que integren la estructura de la persona jurídica. En un orden jerárquico, estas personas pueden ser aquellas con facultades de decisión, y que en el marco de estas se encomiende la realización un ilícito, aunque, no necesariamente de manera clara, puede incluso ser por omisión o hasta negligencia. Así también pueden ser personas con facultades de control o algún poder de mando, como un gerente. Y por último, puede ser por representación; aquí pueden incluirse hasta los empleados. De esta manera se exige ese hecho de conexión de los elementos personales que conforman la estructura societaria para poder imputar a la persona jurídica un ilícito, ya que se entiende que esta tiene un papel de garante, en cuanto tiene un deber de vigilar el cumplimiento de una correcta organización a fin de evitar ilícitos. ${ }^{15}$
Una ventaja de esta teoría es que permite comprobar el dolo o la culpa no en la persona jurídica, sino de sus integrantes. Se trata, en consecuencia, de una culpabilidad dolosa o imprudente referida al propio defecto de organización y a la relevancia que tiene tal defecto para la omisión de los hechos delictivos (Benítez, 2009, p. 208)

\section{Consideraciones finales}

Realizar un planteamiento general de este tema resulta escabroso, por no decir casi imposible. En tanto, carecemos de una ley general que determine la situación jurídica de las personas jurídicas, además de no contar con una jurisprudencia que se postule ante el tema. Por ello, no queda más que recurrir a la doctrina. Sin embargo, la misma doctrina administrativa es vacilante ante el tema. Así, al mencionar las paradojas y sarcasmos de Nieto, en este tema se considera como el giro hacia el Derecho penal. Ya que, desde la admisión de la responsabilidad penal de las personas jurídicas en España, ha sido la doctrina penalista la encargada de un desarrollo dogmático en la temática, que supera a la administrativista; y que incluso el legislador español ha creado disposiciones generales de dicha responsabilidad, estableciendo los dos sistemas anteriormente desarrollados.

\section{Referencias}

Benítez, J.G. (2009). "La responsabilidad penal de las personas jurídicas y las medidas del artículo 129 en el anteproyecto de 2008 de reforma del código penal". Cuadernos penales José María Lidón, 208.

Cavero., P.G. (2012). "Esbozo de un modelo de atribución de responsabilidad penal de las personas jurídicas". Revista de Estudios de la Justicia, $n .^{\circ} 16,61-62$.

Coria, D.C. (2001). "La responsabilidad de la propia Persona Jurídica en el Derecho Penal peruano e iberoamericano". Revista de Derecho PUCP $n .^{\circ} 54,420$.

Giannini, M. (1991). Derecho Administrativo. Madrid: Miniserio para las Administraciones Públicas.

15 Tal sistema ha engendrado alguna crítica en dicho punto. Así, García Cavero menciona que a la propuesta de la culpabilidad por defecto de organización se le ha cuestionado no seguir, en realidad, un modelo de autoresponsabilidad, sino mantenerse en un modelo de atribución del hecho de otro. De manera general, se ha dicho que la defectuosa organización es finalmente consecuencia de la actuación indebida de los órganos de control o supervisión a la empresa, por lo que se seguiría trabajando con el modelo de transferencia de la responsabilidad penal. Este cuestionamiento presupone, sin embargo, que sea posible reconducir la forma de organización de la persona jurídica completamente a la decisión de un órgano de control o supervisión, lo que parece poco plausible, al menos, en organizaciones con cierto grado de complejidad. Por esta razón, no parece razonable calificar, en general, a la culpabilidad por defecto de organización como modelo de atribución de hecho de otro. Sin embargo, no puede desconocerse que mantiene muchos rasgos de heteroresponsabilidad, como la necesidad de un hecho de conexión realizado por el órgano o representante, pero sobre todo la negación de supuestos de exculpación en relación con la culpabilidad propia de la persona jurídica (Cavero, 2012, pp. 61-62). 
Kuri, J. (2013). Imputaión a la víctima de delitos de resultado en México. México: Unam.

Lopez, J.B. (Madrid). “Derecho Administrativo Sancionador, el principio de culpa y las personas jurídicas". La responsabilidad penal de las sociedades. Actuación en nombre de otro. Responsabilidad de los consejos de administración. Responsabilidad de los subordinados. Cuadernos de Derecho Judicial, CGPJ, 145.

M. Rebollo Puig; M. Izquierdo Carrasco; L.A. Alarcón Sotomayor; A.M. Bueno Armijo. (2010). Derecho Administrativo Sancionador. España: Lex Novo.

M.J., G.C. (2008). Los principios de la potestad sancionadora teoría y práctica. España: Iustel.

Montalvo, J.C. (2009). "Criterios de atribución de responsabilidad en el seno de la persona jurídica en el artículo 31 bis del texto proyectado". Cuadernos penales José María Lidon, 292.

Nieto, A. (2012). Derecho Administrativo Sancionador. España: Tecnos.
Pasamar, M.B. (Estudios Penales y Criminológicos). La introducción de la responsabilidad penal de las personas jurídicas en la legislación española.

Sánchez, J.B. (2010). Personas y Derechos de la personalidad. Madrid, España: Reus.

Sánchez, J.S. (2009). El contexto del Anteproyecto de reforma del Código Penal de 2008. Bilbao.

Santos, V.C. (2001). Derecho Sancionador y Mercado de Crédito, con los cambios producidos tras la creación del Banco Central Europeo. Barcelona: BOSH.

Teso, A. D. (s.f.). El principio de culpabilidad en el Derecho Administrativo Sancionador.

Tomillo, M.G. (2010). Introducción a la responsabilidad penal de las personas jurídicas en el sistema español. España: Lex Nova.

Torrado, M.R. (2008). "Consideraciones de la Corte Constitucional acerca del principio de culpabilidad en ámbio sancionador administrativo". Revista de Derecho numero 029, Universidad de los anades, 172. 